\title{
Article \\ Investigation of Regenerative Braking Performance of Brushless Direct Current Machine Drive System
}

\author{
Omer Cihan Kivanc $1,2, \ddagger$ (D) and Ozgur Ustun $2,3, *,+, \ddagger(\mathbb{D}$ \\ 1 Department of Electrical and Electronics Engineering, Istanbul Okan University, Istanbul 34959, Turkey; \\ cihan.kivanc@okan.edu.tr \\ 2 Mekatro Mechatronics Systems R\&D Co., ITU Ari Teknokent, ARI-2/B, Istanbul 34469, Turkey \\ 3 Department of Electrical Engineering, Istanbul Technical University, Istanbul 34469, Turkey \\ * Correspondence: oustun@itu.edu.tr or oustun@mekatro.com; Tel.: +90-212-285-3338 \\ † Current address: Department of Electrical Engineering, Istanbul Technical University, Istanbul 34469, Turkey. \\ $\ddagger \quad$ These authors contributed equally to this work.
}

Citation: Kivanc, O.C.; Ustun, O. Investigation of Regenerative Braking Performance of Brushless Direct Current Machine Drive System. Appl. Sci. 2021, 11, 1029. https://doi.org/ 10.3390/app11031029

Academic Editor: Muhammad Aziz Received: 14 December 2020 Accepted: 21 January 2021 Published: 24 January 2021

Publisher's Note: MDPI stays neutral with regard to jurisdictional clai$\mathrm{ms}$ in published maps and institutional affiliations.

Copyright: $(2021$ by the authors. Licensee MDPI, Basel, Switzerland. This article is an open access article distributed under the terms and conditions of the Creative Commons Attribution (CC BY) license (https:// creativecommons.org/licenses/by/ $4.0 /)$.
Abstract: The brushless direct current (BLDC) machines which are preferred in light electric vehicles (LEVs) come forward as high regenerative braking capability machines due to their permanent magnet excitation and relatively simple operation. In this paper, the regenerative braking capability limits of BLDC machines and their drive circuits are examined by taking into account nonlinear circuit parameters and battery internal resistance variation. During energy recovery from mechanical port to electrical port, the inverter of BLDC machine is operated as a boost converter which enables power flow to a battery. However, the regeneration performance is also heavily dependant on the battery condition, particularly the temperature. By means of the developed detailed circuit model including the non-ideal effects of the boosting converter and the increase of the internal resistance variation which is caused by the temperature variation of the battery and ambient temperature, the specific duty cycle can be determined. The specific duty ratio is then applied in a proposed approach for various operation scenarios. The experimental tests are implemented by a $400 \mathrm{~W}$ BLDC machine drive system controlled via a TMS320F28335 digital signal processor. The experimental results show that the proposed comprehensive model presents a proper performance estimation of regenerative braking system under varying battery temperature.

Keywords: regenerative braking; brushless direct current machine; parameter variation; light electric vehicle

\section{Introduction}

It is essential to implement regenerative braking in all types of electric and hybrid vehicles to extend traveling distance which is hindered by a limited battery capacity $[1,2]$. Mostly, regenerative braking is applied during downhill driving and when speed limitation is needed [3,4]. Providing appropriate deceleration or braking in downhill driving, regenerative braking brings both energy regain and safety with its retarding effect [5]. Extra traveling distance due to regaining of some spent energy back is one of the solutions for "range anxiety" as well as for the total efficiency of an electric power train [6-8]. An optimistic guess is to provide $10 \%$ to $15 \%$ of energy back to the battery by regeneration [9]. Basically, there are some inherent limitations of regenerative braking such as the braking capability of the vehicle electric powertrain, the battery's state-of-charge (SoC), ambient temperature, etc. [10,11]. Firstly, regenerative braking is not implemented with a fully charged battery and causes heating for some operation schemes. So, there must always be room for extra charging kept in the battery capacity. Vehicle weight distribution while cornering or braking is also a limiting factor for regeneration performance [12]. Of course, regenerative braking efficiency is highly related to operation regions of electrical machines and their power electronic systems [13]. Most of all, efficiency is limited at lower speeds due to reduced induced voltage and low 
power amount. To mitigate those disadvantages and improve the performance of regenerative braking, a number of publications are presented in the literature.

In [14], a new method for regenerative braking in electric vehicles is presented. The proposed approach is a combined version of single-switch, two-switch, three-switch, and plugging operations in brushless direct current (BLDC) machines and the coordination of them according to their higher performance regions. Those operation regions are verified by means of a criteria consisting of boosting the converter ratio, braking torque, maximum conversion ratio, stopping time, and energy recovery value. In [13], an integrated fuzzy and PID (proportional-integral-derivative) controller is implemented for braking torque distribution. The proposed method brings a better performance of regenerative braking over conventional control methods related to robustness and efficiency. In addition, for fuzzified input parameters, the battery SoC, speed of vehicle, and brake force are selected. In another publication, a real-time range indicator system is developed and an on-board estimation algorithm for $\mathrm{SoC}$ and travel range is implemented according to real-time data captured from environmental units [15]. Weather conditions, rolling resistance, ambient temperature, power train efficiency, real-time traffic data, and regenerative-frictional braking force distribution are taken into account for the presented study. In [16], an energy optimized driving strategy is realized for heavy-duty vehicles. For model predictive control (MPC) method, regenerative braking is used as an optimization parameter. Another study is about a braking force control strategy and a sharing algorithm between regenerative braking and frictional braking for maximizing regenerative braking efficiency [12]. In [17], the maximum regenerative braking force for a vehicle is obtained by analyzing the braking capability of a $\mathrm{PM}$ synchronous motor. The maximum regenerative braking effort is used as a constraint for a MPC. By means of that parameter, the braking torque value is determined according to driving tendencies of user. Furthermore, the emergency braking is implemented to provide the shortest stopping distance by using a sliding mode controller. Another publication is on the regenerative braking capacity of a specific electric machine at lower speeds by analyzing the limiting factor of regeneration [18]. Additionally, a novel control approach based on the monitoring of a dc-link current of the motor controller is proposed to overcome the limitation and enable dynamic detection of a low-speed cutoff point (LSCP). In [19], the regenerative braking performance of an electrical machine is enhanced by using a downshifting system at the machine operation points. A load commutated multilevel current source inverter fed open-ended winding induction motor drive with regeneration capability is presented in [20]. The proposed approach is related to a decrease in the effect of low back EMF and increase in the amplitude of regenerative braking torque. In [21], a slip-rate control strategy based on sliding mode control and braking force control strategy based on the Economic Commission for Europe's (ECE) regulation are presented to improve the efficiency of recovered electrical energy. A novel two-boost method which is exploiting the motor converter as a cascade connected two-level boost converter is asserted for BLDC motor regenerative braking [22]. In [23], a downshifting strategy is described to improve recovery energy by adjusting operating regions of electric motor for electric and hybrid vehicles with stepped automatic transmissions. The method proposal includes a downshifting control strategy using cluster-based stochastic dynamic programming (SDP).

Although numerous methods and approaches are presented in recent literature, most of them accommodate complex mathematical modeling or additional circuits and of course, those extra features hinder the possibilities of practical application of regenerative braking. The suitable solution implies not using any additional circuits, implementing a braking control strategy without compromising the regenerative braking performance [24]. The fundamental principle of regeneration is relied on using an inverter as a boost converter and machine stator winding as boosting inductors. However, this method has some limitations due to the nonlinear effects of the drive circuit. The limitations of voltage boosting are mainly caused by SoC and the thermal structure of a battery pack, winding resistance, non-ideal effects, and voltage drops of semiconductors [25]. Battery heating is dependent on ambient and operation conditions [26]. Basically, because of the electrochemical 
structure, heating is a major deteriorating factor for any battery type. In [27], internal resistance and capacity of battery are investigated for different operation conditions. It is indicated that temperature rise due to ambient and/or operation conditions negatively affect power and the energy capacity of a battery and vehicle performance consequently. Sometimes an improper regenerative braking operation may cause overheating which disrupts the overall battery performance [28]. A mathematical approach to single-switch regeneration scheme with maximum conversion ratio for BLDC motors is proposed in [13]. However, the change of internal resistance of battery-related heating is not taken into account. In [15], for a commercial electric vehicle (Nissan Leaf), the variation of battery internal resistance is presented for different $\mathrm{SoC}$ values during charging and discharging. Battery open circuit voltage depending on $\mathrm{SoC}$ and internal resistance shows the effects of ambient temperature and operation conditions. Temperature rise, i.e., heating, affects the performance, reliability, and life span of a battery package. Its effect on internal resistance also hampers regenerative braking efforts [19]. Tracking of internal resistance variation and controlling battery performance improve the quality of regenerative braking.

In this study, all constraints emerge from non-ideal elements of the motor control inverter, which is reduced to a single-switch boost converter model, such as on-state resistances, threshold voltage drops, and dynamic variation of battery internal resistance are taken into account to achieve maximum regeneration at the specific duty ratio. A resistancetemperature characteristic $\left[R_{i}(\Omega), \mathrm{T}\left({ }^{\circ} \mathrm{C}\right)\right]$ determined by the online tracking of the battery temperature is used to define the dynamic value of internal resistance for obtaining specific duty ratio which enables the maximum energy recovery during braking. The proposed model of the machine drive system is used for defining the constraints and upper limits. An accurate and dynamic circuit model can reflect the optimizing battery run time and energy recovery performance.

The rest of this paper is organized as follows: In Section 2, the principle of regenerative braking in a BLDC machine is presented. The braking strategy and circuit analysis are presented in Section 3. In Section 4, the experimental studies and results of the proposed method are presented. Additionally, the findings and comparative results are provided in Section 4. Finally, the conclusion is presented in Section 5. The results of the experimental study on the proposed method provide some important clues for the high efficient regenerative braking performance on BLDC machines.

\section{Principle of Regenerative Braking in BLDC Machine}

Regenerative braking is an essential feature of electric vehicles. Thanks to recovering energy via the generator operation of electric propulsion motor and boosting operation of the motor driver, it is possible to regain some part of kinetic energy as electrical energy for battery charging. Besides, it creates a proper braking effect particularly at higher speeds and increases overall efficiency. At a given speed, kinetic energy due to mass and rotating parts of a vehicle can be directed to battery charging while a braking action is applied. Energy, which causes the deceleration of a vehicle is partly recovered to charging the battery pack. Of course, the efficiency of generated electrical energy is dependent on combined operations of the electrical machine and power electronic circuit. If the battery is fully charged, regenerated energy can be consumed in a braking resistor, i.e., dynamic braking. In this study, the kinetic energy storage is implemented by using a flywheel coupled to the BLDC machine, to simulate a light electric vehicle powertrain. So, the braking effect can be easily calculated from the known value of kinetic energy change. However, there are retardation effects in the system other than regenerative braking, namely bearing friction and ferromagnetic (iron) loss due to interaction between stator magnetic core and rotor permanent magnets. The analysis can be complex due to the decomposition of those retarding components. To overcome this problem, a slotless BLDC motor topology which has negligible iron loss, is chosen. This way, the kinetic energy at the start of deceleration, the retarding effect of bearings, and the applied regenerative braking 
can be easily calculated. The regenerative braking action of a BLDC machine, which is driving a flywheel can be summarized as:

$$
\frac{1}{2} J_{T} \omega_{1}^{2}=\frac{\int_{0}^{T_{d}} v_{d}(t) i_{d}(t) d t}{\eta_{R}}+W_{f r}\left(T_{d}\right)
$$

where $J_{T}, \omega_{1}, \eta_{R}, v_{d}, i_{d}, T_{d}, W_{f r}$ are the total inertia of rotating system, angular speed at the starting of deceleration, regeneration efficiency, instantaneous DC-link voltage, i.e., battery terminal voltage, instantaneous DC-link current, i.e., battery charging current, deceleration time to zero, and frictional braking energy of bearings, respectively. Frictional braking energy can be determined by calculating the difference between the free deceleration time and the deceleration time with regenerative braking. It defined as:

$$
W_{f r}\left(T_{d}\right)=\int_{0}^{\theta_{d}} \tau_{f r}(\theta) d \theta
$$

where $\tau_{f r}$ and $\theta_{d}$ are the frictional torque and angular distance taken during deceleration, respectively. The main source of that viscous friction is split roller bearings of the flywheel and there is a contribution from the bearings of motor. Thanks to slotless brushless DC motor topology, there are no losses due to commutator-brush and stator core-permanent magnet interactions.

\section{Proposed Braking Strategy Based on Critical Duty Ratio Determination}

In the proposed study, the model of BLDC machine inverter reduced to a single-switch boost converter circuit is used to elucidate the regenerative braking operation. Single switch is capable of producing required braking torque and better energy recovery in mid to high-speed range [14]. The main principle during regenerative braking is to change the switching scheme to send the recovered energy back to battery, as it can be seen in Figure 1, instead of using regular motor drive switching. The circuit operation includes two states of basic voltage boosting operation: Storing phase and energizing phase. In the regenerative braking operation at the energy storing state, the bottom MOSFETs, $S_{4}, S_{6}$, and $S_{2}$ are switched accordingly to form a braking current waveform for providing proper braking performance. A nearly trapezoidal back electromotive force (EMF) is rectified and boosted by the motor driver converter for charging battery. When a bottom switch is off, the related top and bottom diodes transfer the power, i.e., current, to the battery. Figure 2 shows one operation interval of the converter, when $S_{6}$ and $D_{4}$ are on, the energy stored in the boosting inductor, i.e., the machine winding inductance, due to the terminal induced voltage. Then the current due to the sum of $E_{L}$ and the inductor voltage is sent to the battery through $D_{1}$ and $D_{6}$. $E_{L}$ is the phase-to-phase or line-induced voltage during the generator operation of the BLDC motor and boosting the motor converter's operation, given as:

$$
E_{L}=2 E_{\max }=e_{a}-e_{b}=e_{b}-e_{c}=e_{c}-e_{a}
$$

where $E_{\max }$ is the maximum value of phase induced voltage. For trapezoidal back EMF motors, $E_{L}$ is almost a constant voltage for each $60^{\circ}$ overlapping of the phase induced voltages. For each $60^{\circ}$ of commutation interval of the BLDC motor, $E_{L}$ can be assumed a DC voltage then the converter is operated as a cascade connected rectifier - boost converter. $e_{a}$, $e_{b}$, and $e_{c}$ are the phase-induced voltages of the phase a, phase $\mathrm{b}$, and phase c, respectively. $E_{L}$ can be assumed at its maximum for $60^{\circ}$ intervals, coinciding with the energizing intervals of the BLDC motor. Thus, in the study, the same $60^{\circ}$ conduction intervals provided by Hall sensors are used to define the range in which $E_{L}$ is the highest then the boosting operation by a specified transistor is implemented. 


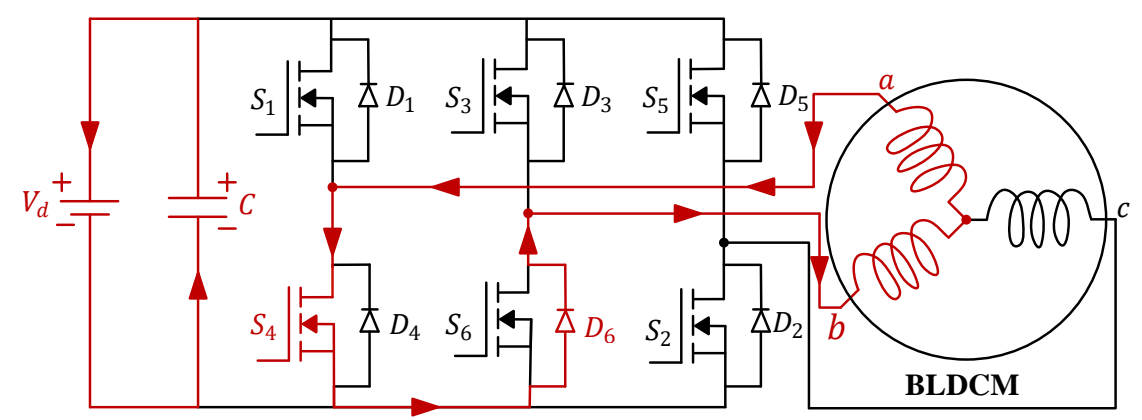

(a) Storing mode

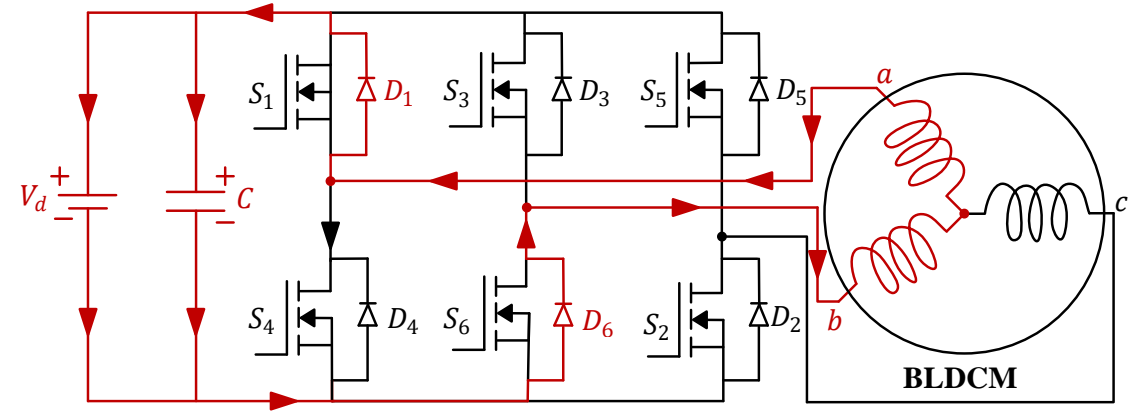

(b) Energizing mode

Figure 1. The circuit operation includes two states of basic voltage boosting operation: storing mode and energizing mode.

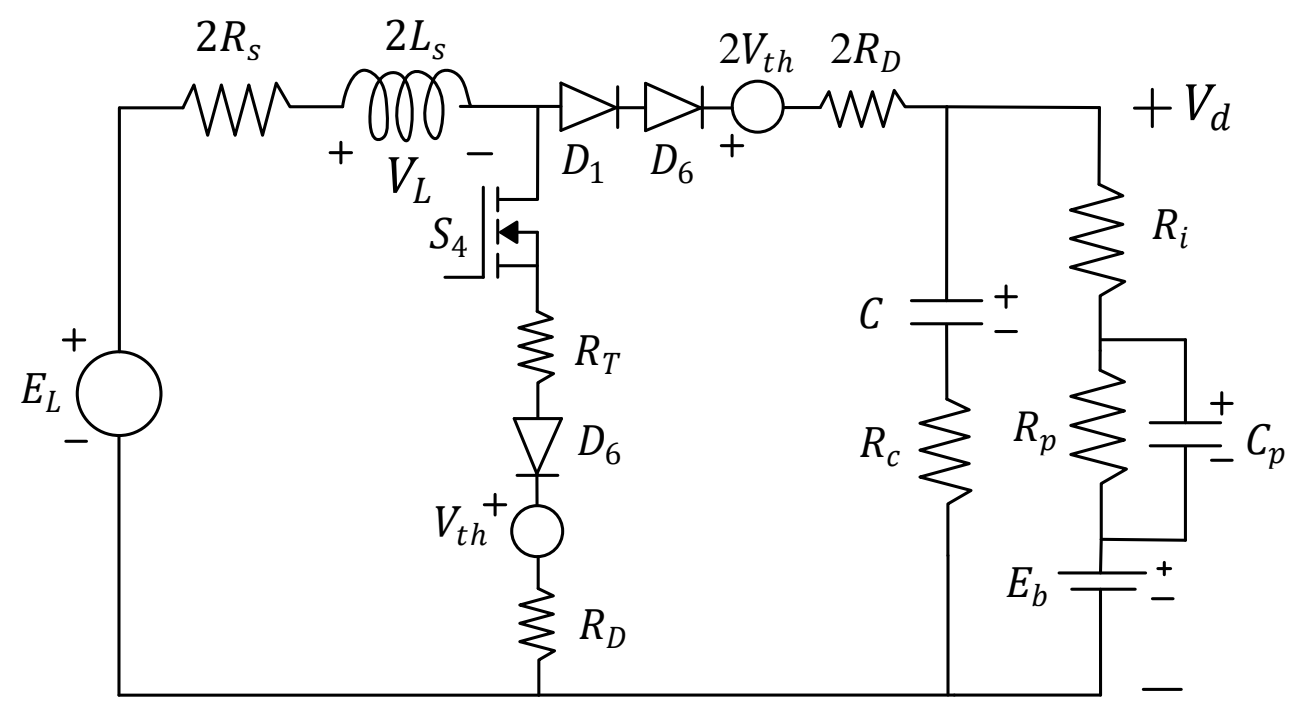

Figure 2. Boost converter equivalent circuit of a powertrain.

By investigating the nature of regenerative braking, it is known that the boostedinduced voltage must compensate all non-ideal voltage drops in the principal circuit [10]. This boosting action is modeled by using a non-ideal boost converter, which is demonstrated in Figure 2 as a lump-parameter equivalent circuit. The non-ideal and parasitic components reduce the boosting action in their extent. For this reason, all nonlinear components should be taken into account while analysis of the circuit and modeling of the whole system are being derived. These analyses are crucial for the regenerative braking performance in order to increase the efficiency and to provide comfortable braking. The stator windings are used as the storing inductors in the boost-operated converter during 
regeneration. Naturally, the inductance value of those windings is higher than that of a conventional boost converter because the main intention is to design a BLDC motor stator winding, although the slotless topology of the motor diminishes the winding inductance to some extent. The main source of loss is the resistance value of the boosting inductor formed by stator windings because of the high number of winding turns. The approximate solutions are made by assuming small-ripple inductor current. The DC voltage gain solution is based on the inductor voltage variation along a switching period. Of course, a certain amount of loss is due to ESRs (equivalent series resistor) of DC-link capacitors. However, thanks to low a ESR and parallel connected DC-link capacitors, the loss caused by ESR is neglected for a steady-state DC solution. Another loss source is the ferromagnetic material of stator core, i.e., inductor core, this loss amount can be easily negligible but due to the slotless stator design. For the sake of simplicity of overall calculation and the implementation of control algorithm, those two loss components are not taken into account.

For steady-state voltage equation, $V_{d}$ is the DC bus voltage which is the boosted value of $E_{L}$, the terminal back-EMF voltage. The most important performance parameter of the system is duty ratio which plays a role in providing enough current from boosted voltage to battery. Duty ratio has its maximum value that the boosted voltage decreases dramatically even as the duty ratio is increased as shown in Figure 3. Ultimately the battery charging current during regeneration, i.e., braking current, must be controlled effectively in order to use high performance regenerative braking. The second limitation is back-EMF. Since $D_{\max }$, which is the maximum duty cycle, depends on the (terminal resistance)/(battery internal resistance) boost conversion ratio, the internal resistance of the battery is an inevitable limitation.

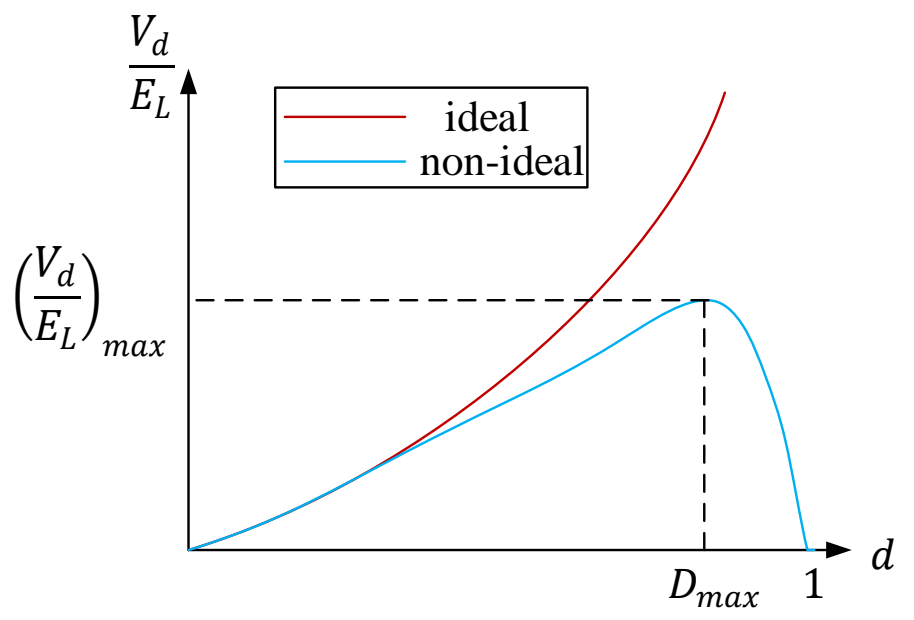

Figure 3. Ideal and non-ideal boosting curves.

When the regenerative braking equivalent circuit operates at a continuous conduction mode (CCM), the circuit can be analyzed by using two switching states as shown in Figure 1. For both cases, all considerable parasitic and non-linear elements are included and the output voltage $\left(V_{d}\right)$ and the load current $\left(i_{d}\right)$ expressions are obtained as presented in Equations (4) and (5).

$$
\begin{array}{r}
V_{d}=\frac{f\left(D_{r}\right)}{g\left(D_{r}\right)}=\frac{E_{b}\left(D_{r} R_{T}+2 R_{s}+2 R_{D}+D_{r} R_{D}\right)+\left(1-D_{r}\right)\left(R_{i}+R_{p}\right)\left[E_{L}-\left(2-D_{r}\right) V_{t h}\right]}{\left(R_{i}+R_{p}\right)\left(D_{r}-1\right)^{2}+\left(D_{r} R_{T}+2 R_{s}+2 R_{D}+D_{r} R_{D}\right)} \\
i_{d}=\frac{\frac{E_{b}\left(D_{r} R_{T}+2 R_{s}+2 R_{D}+D_{r} R_{D}\right)+\left(1-D_{r}\right)\left(R_{i}+R_{p}\right)\left[E_{L}-\left(2-D_{r}\right) V_{t h}\right]}{\left(R_{i}+R_{p}\right)\left(D_{r}-1\right)^{2}+\left(D_{r} R_{T}+2 R_{s}+2 R_{D}+D_{r} R_{D}\right)}}{R_{i}+R_{p}\left(1-e^{-t /\left(R_{p} C_{p}\right)}\right)}
\end{array}
$$


where $V_{d}, D_{r}, V_{t h}, R_{i}, R_{T}, R_{D}, E_{b}, R_{s}, R_{p}, C_{p}$ are the battery voltage, specific duty ratio, diode voltage drop, total battery internal resistance, MOSFET on-resistance, diode onresistance, battery open circuit voltage, stator resistance, total electrochemical polarization resistance, and total electrochemical polarization capacitance, respectively. The duty ratio for maximum voltage gain can be calculated by equating the denominator of Equation (4) to zero. Using the known values of Equation (4) the required duty ratio for the maximum regeneration effect is calculated:

$$
\frac{d g\left(D_{r}\right)}{d D_{r}}=0
$$

The essential performance parameter of the system is the specific duty ratio which provides a proper charging current for the battery pack. The value of $D_{r}$ which is heavily dependent on the internal resistance of the battery has an important limitation. If nonideal circuit parameters are not excluded, the PWM will be applied according to the steady-state and ideal machine equations. At this point, if the total internal resistance variation depending on the battery temperature is not known, an excessive current will charge the battery and cause the system to overheat and be damaged. Thus, in order to achieve a regenerative braking performance at maximum efficiency, the transfer functions including parasitic elements must be obtained. The line-to-output and control-to-output transfer functions of a boost converter model including parasitic elements are derived for regenerative braking operation at $\mathrm{CCM}$. The line-to-output $\left(H_{g}(s)\right)$ and control-to-output $\left(H_{c}(s)\right)$ transfer functions have been obtained to examine the control performance of the specific duty ratio as shown in Equations (7) and (8).

$$
\begin{gathered}
H_{g}(s)=\frac{D_{r}\left(1+s C R_{c}\right)}{s^{2} C\left(1+\frac{R_{c}}{R_{i}}\right) 2 L_{s}}+\frac{D_{r}\left(1+s C R_{c}\right)}{s\left(C\left(1+\frac{R_{c}}{R_{i}} D_{r}\left(R_{T}-R_{D}\right)\right)\right)} \\
+\frac{D_{r}\left(1+s C R_{c}\right)}{\left.\frac{2 L}{R_{i}}\right)+C R_{c}}+\frac{D_{r}\left(1+s C R_{c}\right) R_{i}}{D_{r}\left(R_{T}-R_{D}\right)+2 R_{s}+R_{D}+R_{i}} \\
H_{c}(s)=\frac{\left(E_{L}-i_{d}\left(R_{s w}-R_{d}\right)-V_{t h}\right)\left(1+s C R_{c}\right)}{s^{2} C\left(1+\frac{R_{c}}{R_{i}}\right) L_{s}} \\
+\frac{\left.\left(E_{L}-i_{d}\left(R_{T}-R_{D}\right)-V_{t h}\right)\right)\left(1+s C R_{c}\right)}{s\left(C\left(1+\frac{R_{c}}{R_{i}} D_{r}\left(R_{s w}-R_{d}\right)+\frac{2 L_{s}}{R_{i}}+C R_{c}\right)\right)} \\
+\frac{\left.\left(E_{L}-i_{d}\left(R_{s w}-R_{d}\right)-V_{t h}\right)\right)\left(1+s C R_{c}\right) R_{i}}{D_{r}\left(R_{s w}-R_{d}\right)+2 R_{s}+R_{d}+R_{i}}
\end{gathered}
$$

where $L_{s}, R_{c}, R_{d}$, and $C$ are the terminal inductance, the equivalent series resistance of the DC filter capacitor, diode on-resistance, and capacitance, respectively. Moreover, the closed loop controller including the current and speed loops, the parameters are analyzed for the high stability, the maximum efficiency and the useful regenerative braking operation time. The $D_{r}$ value is determined to be 0.78 and is used as a reference for the experimental studies. This value is assigned as a specific regenerative braking duty ratio at $25{ }^{\circ} \mathrm{C}$.

\section{Experimental Study and Results}

The practical features and feasibility of the regenerative braking circuit model of a BLDC machine drive system are evaluated by using an experimental setup which is presented in Figure 4. Equations (4)-(6) and the braking control scheme are implemented via TMS320F28335 digital signal processor. Using the known parameters and the measured internal resistance value of Equation (4), the required duty ratio for the maximum regeneration operation is calculated according to the regeneration command. In the meantime, instead of a PI controller, a hysteresis controller is activated and the PWM reference ratio is assigned as the calculated critical value. The converter has a maximum DC-link voltage of $13.5 \mathrm{~V} \times 4$, i.e., $54 \mathrm{~V}$, and a rated RMS (root mean square) current of $5.3 \mathrm{~A}$. The experiments 
are verified using the MAXON EC60 slotless type BLDC machine which is coupled to a specially designed flywheel, as shown in Figure 4. The system specifications, BLDC machine, and flywheel parameters are given in Table 1 . The system specifications and machine parameters such as the terminal resistance, terminal inductance, on-resistance of MOSFET, on-resistance of diode, flywheel inertia have the values of $1.12 \Omega, 0.82 \mathrm{mH}$, $0.024 \Omega, 0.05 \Omega, 0.06089 \mathrm{kgm}^{2}$, respectively.

Table 1. Maxon EC60, the brushless direct current (BLDC) machine and flywheel parameters.

\begin{tabular}{cc}
\hline Parameter & Value \\
\hline Rated power $(\mathrm{W})$ & 400 \\
Nominal voltage $(\mathrm{V})$ & 48 \\
No-load speed $\left(\mathrm{min}^{-1}\right)$ & 3100 \\
Max. continuous current $(\mathrm{A})$ & 5.3 \\
Max. efficiency $(\%)$ & 84 \\
Terminal resistance $(\Omega)$ & 1.12 \\
Terminal inductance $(\mathrm{mH})$ & 0.82 \\
Torque constant $(\mathrm{mNm} / \mathrm{A})$ & 147 \\
Rotor inertia $\left.(\mathrm{gcm})^{2}\right)$ & 831 \\
Mass density $\left(\mathrm{kg} / \mathrm{m}^{3}\right)$ & 7858 \\
Mass $(\mathrm{kg})$ & 10 \\
Surface area $\left(\mathrm{m}^{2}\right)$ & 0.16 \\
Flywheel inertia $\left(\mathrm{kgm}^{2}\right)$ & 0.06089 \\
\hline
\end{tabular}

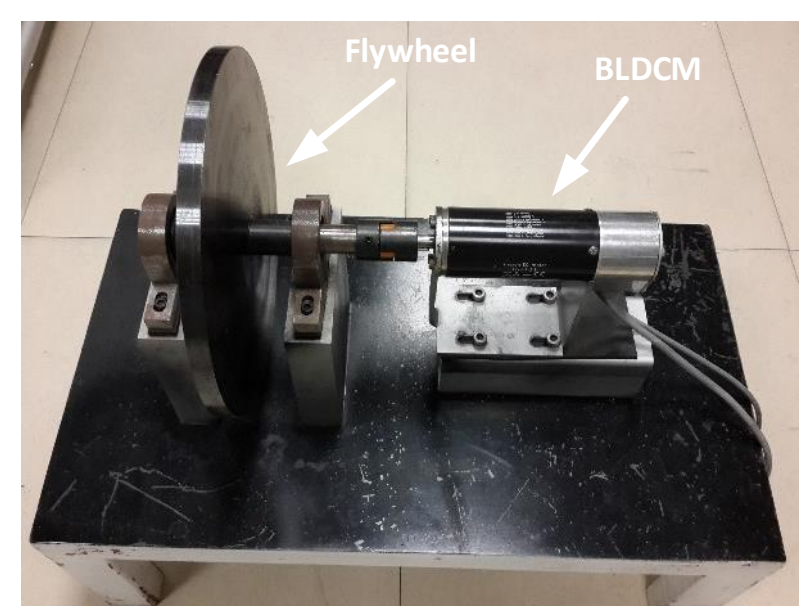

Figure 4. Experimental test bed: Maxon EC60 slotless type BLDC machine coupled to the special flywheel.

In the experiments, the temperature changes are carried out by using an ambient temperature controller for the same $\mathrm{SoC}$ values. The surface temperatures of the leadacid batteries are captured by means of specific temperature sensors. Internal resistance variations are measured at reference points of $25^{\circ} \mathrm{C}, 30^{\circ} \mathrm{C}$, and $35^{\circ} \mathrm{C}$. These values are obtained as $0.909 \Omega, 0.837 \Omega$, and $0.716 \Omega$ at the temperatures $T_{1}, T_{2}$, and $T_{3}$, respectively as shown in Figure 5 In addition, the initial operation parameters are presented in Table 2. 


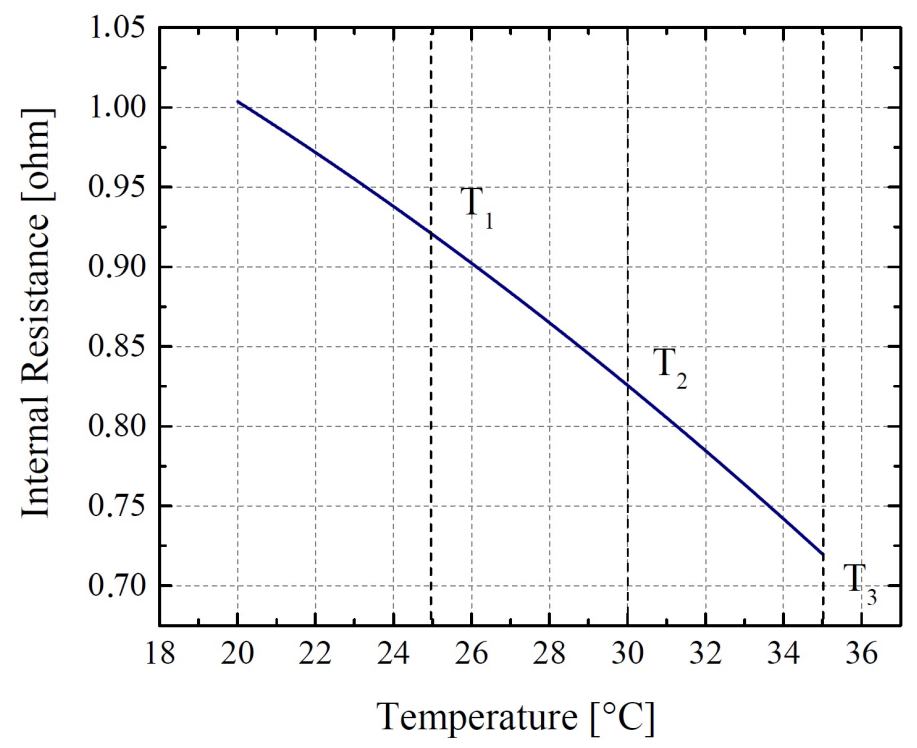

Figure 5. Experimental measurement results of temperature vs. internal resistance variation.

Table 2. Braking operation parameters.

\begin{tabular}{cc}
\hline Parameter & Value \\
\hline Phase-to-phase resistance $(\Omega)$ & 2.24 \\
Diode voltage drop $(\mathrm{V})$ & 1.2 \\
MOSFET on-resistance $(\Omega)$ & 0.024 \\
Diode on-resistance $(\Omega)$ & 0.05 \\
Maximum duty ratio & 0.78 \\
Maximum battery voltage $(\mathrm{V})$ & 56.4 \\
Terminal back-electromotive force $(\mathrm{EMF})$ at starting $(\mathrm{V})$ & 48.4749 \\
Initial internal resistance of a battery $(\Omega)$ & $0.909\left(\right.$ at $\left.25^{\circ} \mathrm{C}\right)$ \\
\hline
\end{tabular}

Figures 6-8 show the results of the experiments for calculated specific duty ratio (0.78). According to Figure 6, at $2.2 \mathrm{~s}$, the regenerative braking has started, causing the voltage to jump from $48.8 \mathrm{~V}$ to $56 \mathrm{~V}$. The output current value of the boosting converter at the starting of regenerative braking is measured as $-6.6 \mathrm{~A}$. Note that a reversal of current occurs when the driver shifts from the inverter to boost converter operation. In this case, the total deceleration time is recorded as $120 \mathrm{~s}$. The specific regenerative braking time is measured as $14.2 \mathrm{~s}$. In Case-2, the temperature of the battery increases to $30^{\circ} \mathrm{C}$ by the heating controller. The internal resistance is measured as $0.837 \Omega$. The voltage increases to $55.7 \mathrm{~V}$ for the specific duty ratio (0.78) in Figure 7. In Figure 8, the voltage of the battery increases to $55.5 \mathrm{~V}$ for the regenerative braking at $35^{\circ} \mathrm{C}$. As can be seen from the experimental results, it is determined that the regenerative braking performance increases for the certain values of the duty ratio. The experimental results for different temperatures and duty ratios are presented in Table 3. 


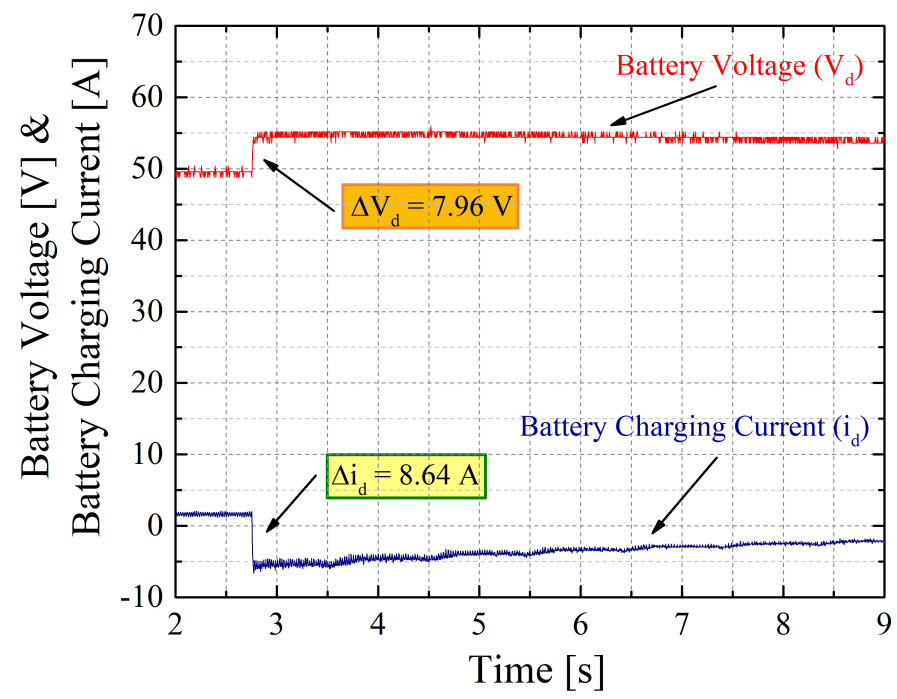

Figure 6. Experimental results for battery voltage and charging current of Case- 1 at $T_{1}$.

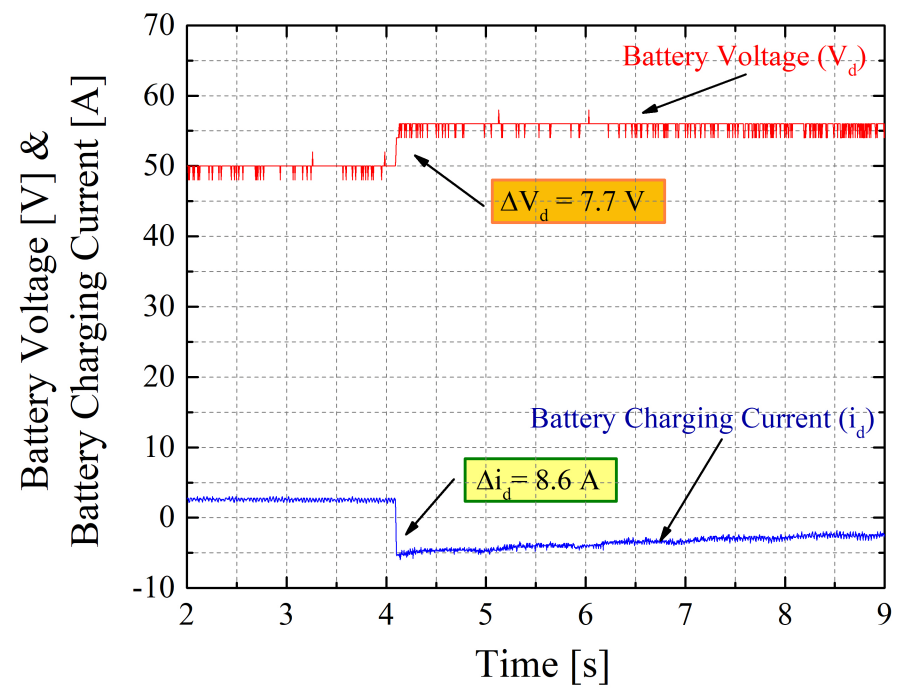

Figure 7. Experimental results for battery voltage and charging current of Case-2 at $T_{2}$.

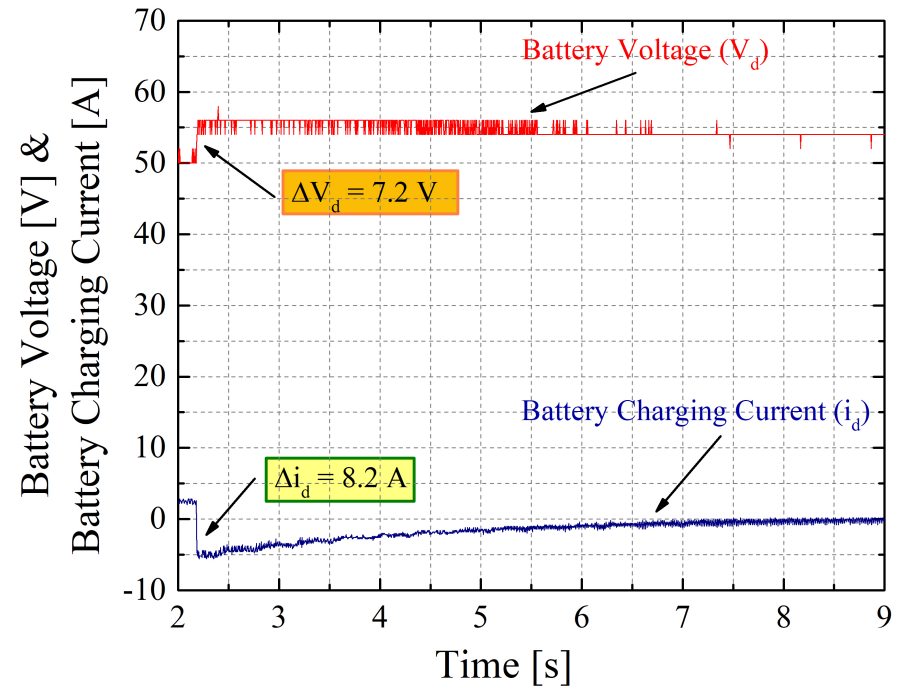

Figure 8. Experimental results for battery voltage and charging current of Case- 3 at $T_{3}$. 
The most critical indication of the experiments is that the regenerative braking performance decreases dramatically if the calculated duty ratio remains unchanged despite varying temperatures. Thus, in order to recover the same amount of energy, 0.78 should be recalculated as 0.792 for $30^{\circ} \mathrm{C}$ and 0.81 for $35^{\circ} \mathrm{C}$.

Table 3. Experimental results.

\begin{tabular}{cccccc}
\hline $\mathbf{T}$ & $\boldsymbol{D}_{\boldsymbol{r}}$ & $\boldsymbol{V}_{\boldsymbol{d}} / \boldsymbol{E}_{\boldsymbol{L}}$ & $\boldsymbol{T}_{\mathbf{1}}$ & Dec. Time & Recovered Energy \\
\hline $25^{\circ} \mathrm{C}$ & 0.78 & 1.147 & $0.909 \Omega$ & $120 \mathrm{~s}$ & $2.9 \mathrm{kWs}$ \\
$30^{\circ} \mathrm{C}$ & 0.792 & 1.147 & $0.837 \Omega$ & $121 \mathrm{~s}$ & $2.87 \mathrm{kWs}$ \\
$35^{\circ} \mathrm{C}$ & 0.81 & 1.147 & $0.716 \Omega$ & $122 \mathrm{~s}$ & $2.83 \mathrm{kWs}$ \\
$25^{\circ} \mathrm{C}$ & 0.78 & 1.147 & $0.909 \Omega$ & $120 \mathrm{~s}$ & $2.9 \mathrm{kWs}$ \\
$30^{\circ} \mathrm{C}$ & 0.78 & 1.137 & $0.837 \Omega$ & $128 \mathrm{~s}$ & $2.65 \mathrm{kWs}$ \\
$35^{\circ} \mathrm{C}$ & 0.78 & 1.128 & $0.716 \Omega$ & $137 \mathrm{~s}$ & $2.47 \mathrm{kWs}$ \\
\hline
\end{tabular}

The electrical measurements are made at the battery terminals, so only the regenerated power and energy values are calculated, the charging efficiency which can be easily calculated by means of the non-ideal battery model is excluded. When all non-ideal variables and the battery temperatures in the energy recovery calculations are taken into consideration, $2.9 \mathrm{kWs}$ of energy is regained as a result of the selected specific duty ratio. The recovered power calculation is performed by capturing the current and voltage variations in the dc-link during the active regenerative braking period. By integrating the product of the current and voltage values on the dc-link, the regenerated energy value is calculated.

In the no-load deceleration tests, the maximum recovered energy is $3.2 \mathrm{kWs}$. In Case- 1 , it can be seen that energy recovery is achieved with a high performance with a ratio of $2.9 \mathrm{kWs} / 3.2 \mathrm{kWs}$. Contrary to this, the energy recovery measurements have shown that in Case-2 and Case-3, 2.65 kWs and $2.47 \mathrm{kWs}$ of energy obtained for $30^{\circ} \mathrm{C}$ and $35^{\circ} \mathrm{C}$, respectively. Filtered voltage waveforms obtained during regenerative braking for Case-1, Case-2, and Case- 3 are presented in Figure 9. Instantaneous battery voltage risings are presented for the same duty ratio (0.78). When the same duty ratio $(0.78)$ is applied, peak value variations of voltages are presented for $T_{1}, T_{2}$, and $T_{3}$ temperatures for different scenarios. In Figure 10, the conversion ratio $\left(V_{d} / E_{L}\right)$ variation is shown for $T_{1}, T_{2}$, and $T_{3}$. The machine deceleration times, which are shown in Figure 11, have been recorded as $128 \mathrm{~s}$ at temperature $T_{2}$, and as $137 \mathrm{~s}$ at temperature $T_{3}$. The performance expected from braking can be measured by the duration of the deceleration time. It is also possible to see how much braking power the vehicle requires to accomplish the expected deceleration time. When all non-ideal variables and battery temperature variation are taken into account, the regained energy amount is about $8.73 \%$ and the value of the calculated duty ratio in the control cycle is revealed.

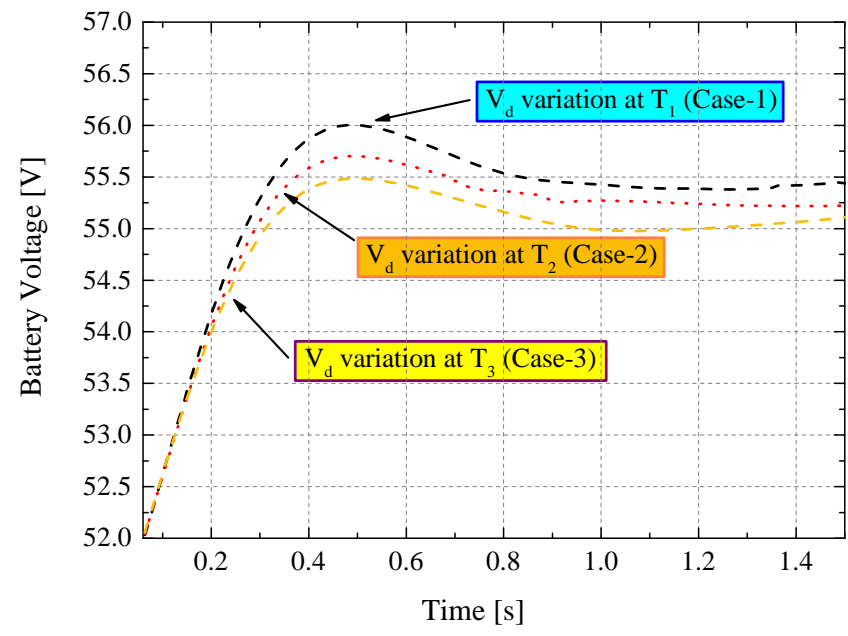

Figure 9. Case-1, Case-2, and Case-3 voltage waveform comparison at braking. 


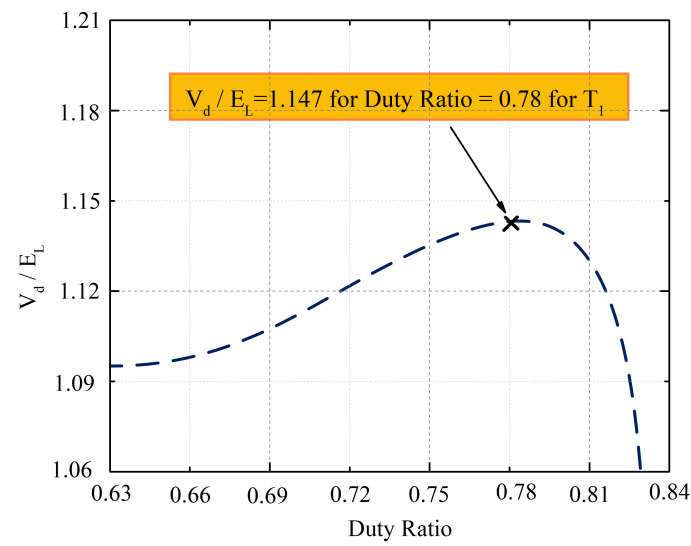

(a) Case-1

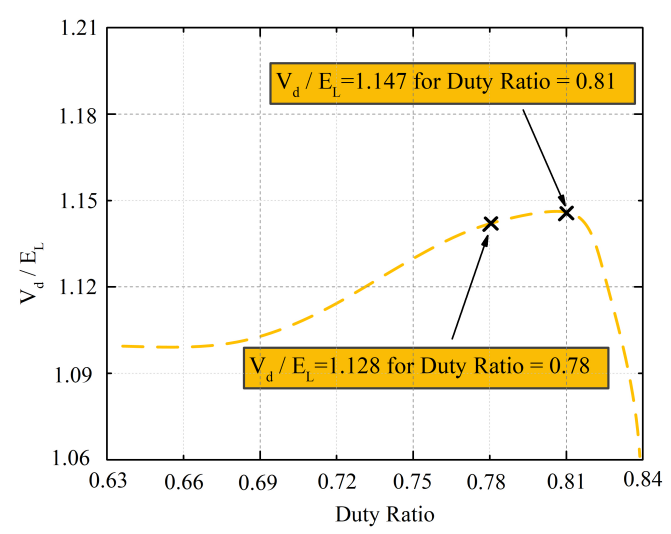

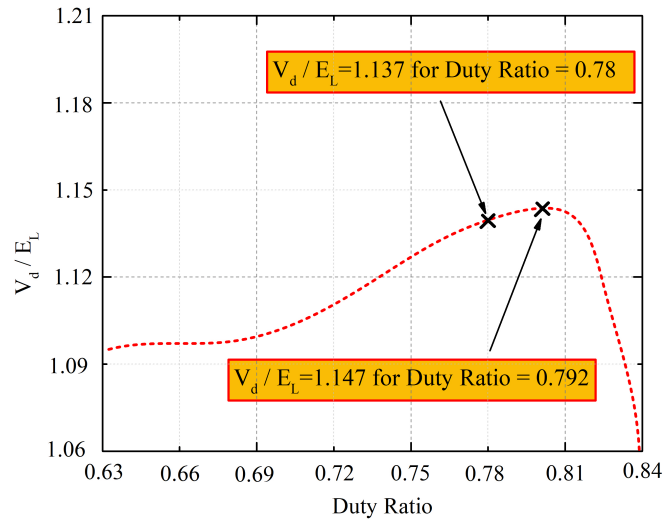

(b) Case-2

(c) Case-3

Figure 10. Maximum conversion ratios for Case-1, Case-2 and Case-3.

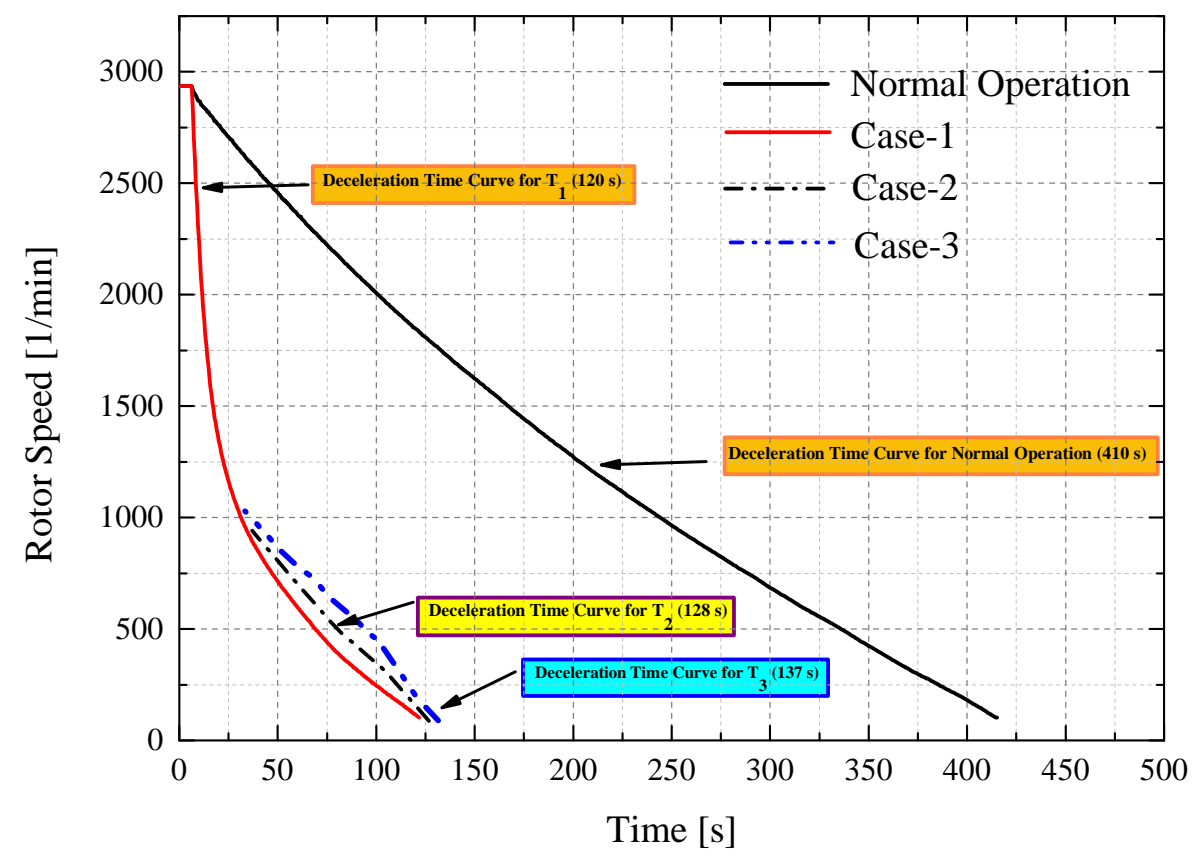

Figure 11. Deceleration time curves for Case-1, Case-2, and Case-3 using a 0.78 duty ratio.

\section{Conclusions}

Regenerative braking is one of the most considerable solutions to "range anxiety" problem of electric vehicles. The overall efficiency of electric vehicle, i.e., well-to-wheel 
efficiency, is increased and the possible emission level is reduced in the case of electric energy generated from fossil fuels. In the study, an accurate model of motor operation, including non-ideal elements of the system, during regenerative braking is formed. A lead acid battery bank is used due to its robustness and safer behavior. The regenerative performance can be changed according to battery type, state, and condition. The experimental study shows that the regenerative braking energy could be improved up to $8.73 \%$ of the total energy capacity of a lead acid battery bank. The study implied the effect of temperature and therefore battery internal resistance changes on the performance of regeneration. The efficiency of regeneration with a controlled braking action is entirely dependent on the operation points of electrical machine, the converter, and battery pack. The non-ideal effects of motor and motor converter must be taken into account to reflect more realistic regeneration performance. The results validated the effectiveness and feasibility of the proposed model. Monitoring the battery condition is an essential part of regenerative braking performance. The same study can be conducted for Li-Ion batteries considering the constraints of the battery type.

Author Contributions: O.U. conceived the research idea, participated in all of the study phases, and provided guidance and supervision. O.C.K. developed software and wrote the original draft. All authors have read and agreed to the published version of the manuscript.

Funding: This research received no external funding.

Institutional Review Board Statement: Not applicable.

Informed Consent Statement: Not applicable.

Data Availability Statement: The data presented in this study are available on request from the corresponding author.

Acknowledgments: The authors also thank Assistant Professor Vedat Temiz for his insightful technical discussions and his valuable feedback, which helped in improving the paper.

Conflicts of Interest: The authors declare no conflict of interest.

\section{References}

1. Bingham, C.; Walsh, C.; Carroll, S. Impact of driving characteristics on electric vehicle energy consumption and range. IET Intell. Transp. Syst. 2011, 1, 29-35. [CrossRef]

2. $\mathrm{Xu}, \mathrm{W}$;; Chen, H.; Wang, J.; Zhao, H. Velocity optimization for braking energy management of in-wheel motor electric vehicles. IEEE Access 2019, 7, 66410-66422. [CrossRef]

3. Liu, H.; Lei, Y.; Fu, Y.; Li, X. An optimal slip ratio-based revised regenerative braking control strategy of range-extended electric vehicle. Energies 2020, 13, 1526. [CrossRef]

4. Xiao, B.; Lu, H.; Wang, H.; Ruan, J.; Zhang, N. Enhanced regenerative braking strategies for electric vehicles: dynamic performance and potential analysis. Energies 2017, 10, 1875. [CrossRef]

5. Liu, H.; Lei, Y.; Fu, Y.; Li, X. Multi-objective optimization study of regenerative braking control strategy for range-extended electric vehicle. Appl. Sci. 2020, 10, 1789. [CrossRef]

6. $\mathrm{Xu}, \mathrm{L} . ; \mathrm{He}, \mathrm{X}$.; Shen, $\mathrm{X}$. Improving energy recovery rate of the regenerative braking system by optimization of influencing factors. Appl. Sci. 2019, 9, 3807. [CrossRef]

7. Chen, R.; Liu, X.; Miao, L.; Yang, P. Electric vehicle tour planning considering range anxiety. Sustainability 2020, $12,3685$. [CrossRef]

8. Neumann, I. Eco-driving strategies in battery electric vehicle use-how do drivers adapt over time? IET Intell. Transport Syst. 2015, 9, 746-753. [CrossRef]

9. Yang, M.; Jhou, H.; Ma, B.; Shyu, K. A cost-effective method of electric brake with energy regeneration for electric vehicles. IEEE Trans. Ind. Electron. 2009, 6, 2203-2213. [CrossRef]

10. Kivanc, O.C.; Ustun, O.; Tosun, G.; Tuncay, R.N. On Regenerative Braking Capability of BLDC Motor. In Proceedings of the IEEE Industrial Electronics Conference, Florence, Italy, 23-26 October 2016.

11. Zhang, X.; Wang, Y.; Liu, G.; Yuan, X. Robust regenerative charging control based on T-S fuzzy slidingmode approach for advanced electric vehicle. IEEE Trans. Transp. Electrif. 2016, 1, 52-66. [CrossRef]

12. Yuan, Y.; Zhang, J.; Li, Y.; Li, C. A novel regenerative electrohydraulic brake system: development and hardware-in-loop tests. IEEE Trans. Veh. Technol. 2018, 67, 11440-11452. [CrossRef]

13. Nian, X.; Peng, F.; Zhang, H. Regenerative braking system of electric vehicle driven by brushless DC motor. IEEE Trans. Ind. Electron. 2014, 61, 5798-5808. [CrossRef] 
14. Godfrey, A.J.; Sankaranarayan, V. A new electric braking system with energy regeneration for a BLDC motor driven electric vehicle. Eng. Sci. Technol. 2018, 21, 704-713. [CrossRef]

15. Sarrafan, K.; Muttaqi, K.M.; Sutanto, D.; Town, G.E. A real-time range indicator for EVs using web-based environmental data and sensorless estimation of regenerative braking power. IEEE Trans. Veh. Technol. 2018, 67, 4743-4756. [CrossRef]

16. Held, M.; Martensson, J. Optimal speed control of heavy-duty vehicle in urban driving. IEEE Trans. Intell. Transp. Syst. 2019, 20, 1562-1573. [CrossRef]

17. Wenfei, L.; Du, H.; Li, W. Driver intention based coordinate control of regenerative and plugging braking for electric vehicles with in-wheel PMSMs. IET Intell. Transp. Syst. 2018, 12, 1300-1311. [CrossRef]

18. Heydari, S.; Fajri, P.; Rasheduzzaman, M.; Sabzehgar, R. Maximizing regenerative braking energy recovery of electric vehicles through dynamic low-speed cutoff point detection. IEEE Trans. Transp. Electrif. 2019, 5, 262-270. [CrossRef]

19. Lin, Z. Measuring range anxiety: the substitution-emergency-detour (SED) method. World Electr. Veh. J. 2012, 5, 8-13. [CrossRef]

20. Richu, S.C.; Rajeevan, P.P. A load commutated multilevel current source inverter fed open-end winding induction motor drive with regeneration capability. IEEE Trans. Power Electron. 2020, 35, 816-825. [CrossRef]

21. Itani, K.; Bernardinis, A.D.; Khatir, Z.; Jammal, A. Comparison between two braking control methods integrating energy recovery for a two-wheel front driven electric vehicle. Energy Convers. Manag. 2016, 122, 330-343. [CrossRef]

22. Bahrami, M.; Mokhtari, H.; Dindar, A. Energy regeneration technique for electric vehicles driven by a brushless DC motor. IET Power Electron. 2019, 12, 3397-3402. [CrossRef]

23. Liu, B.; Li, L.; Wang, X.; Cheng, S. Hybrid electric vehicle downshifting strategy based on stochastic dynamic programming during regenerative braking process. IEEE Trans. Veh. Technol. 2018, 67, 4716-4727. [CrossRef]

24. Chen, Y.C.; Tu, C.H.; Lin, C.L. Integrated electromagnetic braking/driving control of electric vehicles using fuzzy inference. IET Electr. Power Appl. 2019, 13, 1014-1021. [CrossRef]

25. Marcetic, D.P.; Matic, P.R. Non-regenerative braking of permanent magnet synchronous motor. IEEE Trans. Ind. Electron. 2020, 67, 8186-8196. [CrossRef]

26. Wu, J.; Wang, X.; Li, L.; Du, Y. Hierarchical control strategy with battery aging consideration for hybrid electric vehicle regenerative braking controls. Energy 2019, 145, 301-312. [CrossRef]

27. Rugh, J.P.; Pesaran, A.; Smith, K. Electric Vehicle Battery Thermal Issues and Thermal Management Techniques. In Proceedings of the Alternative Refrigerant and System Efficiency Symposium, Scottsdale, AZ, USA, 27-29 September 2011.

28. Iora, P.; Tribioli, L. Effect of ambient temperature on electric vehicles energy consumption and range: model definition and sensitivity analysis based on Nissan Leaf data. World Electr. Veh. J. 2019, 10, 2. [CrossRef] 